\title{
PRODUÇÃO DE FRUTÍFERAS INOCULADAS COM FUNGOS MICORRÍZICOS ARBUSCULARES
}

\author{
Sandro Ferreira Nascimento ${ }^{1}$; Andréa Hentz de Mello ${ }^{2}$ \\ ${ }^{1}$ Discente do curso de Agronomia, Faculdade de Ciências Agrárias de Marabá (FCAM), Universidade Federal do Pará \\ (UFPA), Marabá, Pará. Bolsista PROINT. E-mail: sandro-fn@ hotmail.com. \\ ${ }^{2}$ Prof., D.Sc., FCAM, UFPA. E-mail: andreahentz@ufpa.br.
}

RESUMO: Os solos da Amazônia apresentam limitações à exploração agrícola, como alta acidez e baixa fertilidade, são facilmente degradáveis quando descobertos em função do manejo de corte e queima e abandonados quando não conseguem uma produção sustentável. Diante dessa realidade tem-se buscado alternativas que aumentem a produção, promovendo um desenvolvimento econômico, social e ambientalmente sustentável. Entre elas a adoção de estratégias biológicas, como as associações micorrízicas arbusculares, por promoverem uma melhor nutrição das plantas em Fósforo $(\mathrm{P})$, Nitrogênio $(\mathrm{N})$, e Potássio $(\mathrm{K})$. As associações micorrízicas também tornam as plantas mais tolerantes a períodos secos e temperaturas elevadas, a acidez do solo e protegem o sistema radicular contra patógenos. Assim, as micorrizas podem ajudar na recuperação ou regeneração de áreas degradadas. A diversidade de Fungos Micorrízicos Arbusculares (FMAs), em um ecossistema como o amazônico pode ser determinante na sua produtividade e diversidade vegetal, podendo também a planta exercer influência quantitativa e qualitativa na ocorrência. Nesse contexto os objetivos desse trabalho serão: avaliar a ocorrência e caracterizar a eficiência de FMAs associados às frutíferas cupuaçu (Theobroma grandiflorum), pupunha (Bactris gasipaes), açaí (Euterpe oleracea), abacaxi (Ananás comosus), acerola (Malpighia glabra), cajá (Spondias lutea), goiaba (Psidium guajava) e maracujá (Passiflora sp.), cultivadas em sistema agroflorestal (SAF) e em monocultivo; determinar o potencial de colonização dos FMAs; determinar a dependência micorrízica das frutíferas a serem cultivadas; testar a efetividade de FMAs em promover o crescimento das mudas das frutíferas cultivadas; produzir mudas dessas frutíferas inoculadas com FMAs; verificar qual o melhor substrato para o desenvolvimento das plantas; verificar o desenvolvimento radicular e parâmetros de crescimento das mudas em casa de vegetação e no campo. O trabalho será realizado em casa de vegetação instalada na Universidade Federal do Pará, Campus de Marabá, e nos campos experimentais do MST e da Escola Família Agrícola (EFA). As amostras de solo para a identificação dos fungos micorrízicos arbusculares associadas às culturas de cupuaçu, pupunha, açaí, abacaxi, acerola, cajá, goiaba e maracujá, serão coletadas em áreas de SAFs e monocultivo nos Projetos de Assentamento da região de Marabá. A identificação dos FMAs acontecerá de maneira direta (peneiramento úmido e centrifugação em sacarose 40\%) e indireta (cultivo armadilha de Brachiaria brizantha). As mudas das frutíferas serão produzidas em tratamentos de inoculação de esporos de FMAs, envolvendo diferentes substratos e doses de fósforo e antes de serem levadas a campo serão avaliados parâmetros de crescimento como altura, diâmetro do caule, número de folhas, colonização e dependência micorrízica. Os dados, testados quanto à sua homogeneidade, serão submetidos à análise de variância, teste de média e regressão polinomial, utilizando-se do programa estatístico SISVAR. Espera-se determinar o melhor FMA a ser utilizado na produção de mudas; a criação de um banco de dados sobre a ocorrência, caracterização e eficiência de FMAs nos solos da Amazônia sob o cultivo de pupunha, cupuaçu, açaí, goiaba, cajá, abacaxi e maracujá; implantação de SAFs com mudas inoculadas com FMAs; criação de um banco de inóculo de FMAs; inclusão do tema nas disciplinas de Microbiologia, Fitotecnia e Gestão dos Recursos Naturais.

PALAVRAS-CHAVE: Solos amazônicos, mudas, micorrizas.

Agroecossistemas, v. 1, n. 1, p. 15-15, 2009 